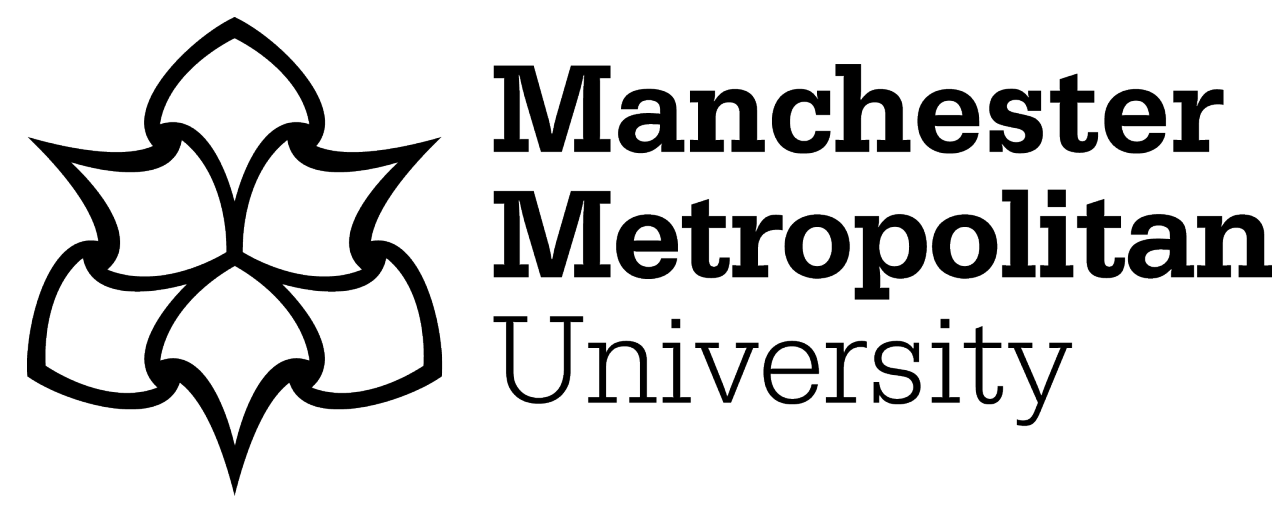

Jack, Kirsten, Ridley, Caroline and Turner, Samuel (2019) Effective communication with older people. Nursing Older People, 31 (4). pp. 40-48. ISSN 1472-0795

Downloaded from: https://e-space.mmu.ac.uk/625192/

Version: Accepted Version

Publisher: RCN Publishing Ltd.

DOI: https://doi.org/10.7748/nop.2019.e1126

Please cite the published version 


\section{Effective Communication with Older People}

\section{Aim and intended learning outcomes}

The aim of this article is to help you to explore effective communication in relation to the needs of older people.

After reading this article and completing the time out activities you should be able to:

- Describe the particular needs of the older person in relation to communication

- Describe the need to explore how our own values and beliefs might impact on communication with older people

- Discuss the changes associated with ageing which might impact on communication

- Outline the influence of ageism on communication with older people

- Summarise ways in which communication could be developed positively in practice with older people

\section{Relevance to the Code}

The Code: Professional Standards of Practice and Behaviour for Nurses and Midwives (Nursing \& Midwifery Council (NMC) 2015) is made up of four themes and nurses are encouraged to apply these to their practice: Prioritise people, practise effectively, preserve safety and promote professionalism and trust. This article relates to The Code in the following ways:

- The Code states that nurse should listen to people and respond to their concerns. This article provides information that nurses can use to develop their communication practice to help older people feel listened to and valued by nurses.

- Information is provided in this article about the particular needs of older people so that nurses can communicate clearly, a main aspect of effective practice as outlined in The Code.

- The Code states that nurse must preserve patient and public safety. This article supports nurses to communicate effectively with older people so that they can recognise situations which might put older people at risk and take appropriate action. 
- This article supports the development of communication competencies which nurses can role model to others, with a view to developing communication with older people. Acting as a role model is a way of promoting professionalism, a major theme of The Code.

\section{Introduction}

There are now almost 12 million people aged 65 or over in the United Kingdom (UK) with 1.6 million aged 85 or over (ONS 2017). The over 85 population is 2.7 times greater than it was in 1971 and expected to continue to increase in the future (Public Health England 2018). The population over 75 is projected to double in the next 30 years and nearly one in five people currently in the UK will live to see their 100th birthday (Department for Work and Pensions 2011). However, even though people are living longer, they do not always do so in good health. Living longer in poor health particular problem for women living in the UK who have been shown to be in worse health than in other parts of Europe (Public Health England 2018). Older people living with long term health conditions will need to make more contact with health services, for example, for health screening and chronic disease management. Therefore nurses need to be able to communicate effectively and have the appropriate knowledge and skills to ensure that older people feel listened to, understood and cared for.

Communication can take many forms and at its most basic, verbal communication it is the interaction between people using noises or words and non-verbal communication is the use of hand gestures, body language, and eye contact (Croston 2018). Basic communication skills are used in social interactions and help communication on an instinctive and primitive level. However, there is a difference between this and therapeutic communication, which is commonly used in more formal situations. Therapeutic communication can be described as a person centred interaction, one which involves the nurse using eye contact, open body language, active listening and physical contact. Empathy, silence and respect for the other person are important aspects of therapeutic communication along with nurse wellbeing (Stockmann et al 2016). Concurring with Stockmann et al (2016) Hammar et al (2017) suggests that when building relationships, there are three separate subcategories of communication; seeing the individual, being respectful, and 
showing empathy and compassion. These subcategories are complex in themselves, being respectful for example, is not just the act itself, but having the ability to tailor communication around the individual, whilst maintaining the dignity and compassion required to maintain a positive relationship. Using therapeutic communication to tailor messages to the individual is important and can support the delivery of health related knowledge thereby promoting health and well-being (Williams 2013).

Effective communication is central to the development of a therapeutic relationship although social negativity around ageing can negatively influence this process. Schroyen et al. (2017) suggest that older age can be viewed by professionals to be negative and linked to poor cognition, weakness and resistance to change. For an older person, having the ability to communicate effectively with another person is central to their self-esteem, identity and quality of life (Tolson \& Brown-Wilson 2012). For the professional, effective communication is essential so that they can understand and assess the older person and promote their health (Hafskjold et al 2016). However communication with older people can sometimes be ineffective and based on a transactional, e.g. the performing of medical tasks, rather than person centred model. Older people report being treated with lack of respect and being given insufficient information and negative attitudes from nursing staff can adversely affect the communication exchange (Hanson 2014, Harrison et al 2016). It is important that communication is effective to enhance the quality of care provision and further, to identify potential serious issues such as abuse of the older person.

\section{Effective Communication}

Listening to older people is central to the promotion of person centered care and dignity (Dickson et al 2017). Listening effectively requires us to be self-aware and have the ability to fully focus on the older person and what they are saying. Trevithick (2010) describes multiple skills associated with listening which include good eye contact, having an open body posture and picking up on cues or phrases spoken by the older person. Moss (2012) identifies three skills which can be utilised to show to the older person that we are listening attentively to what they are saying. It is important that these are used sensitively and not in a mechanistic way. These are summarized in Table 1.

\section{Table 1}




\begin{tabular}{|l|l|}
\hline Summarising & $\begin{array}{l}\text { From time to time, summarise what the } \\
\text { older person had been saying. } \\
\text { Summarising the main points of the } \\
\text { story demonstrates that the nurse has } \\
\text { been listening and supports the } \\
\text { development of empathy }\end{array}$ \\
\hline Paraphrasing & $\begin{array}{l}\text { Paraphrasing can be used to pick up on } \\
\text { a particular phrase or sentence used } \\
\text { and reflect it back to the older person. } \\
\text { Paraphrasing parts of the story shows } \\
\text { that the nurse has been listening to the } \\
\text { detail and is trying to get more clarity }\end{array}$ \\
\hline Clarifying & $\begin{array}{l}\text { Clarifying can help the older person to } \\
\text { put their feelings into words and helps } \\
\text { the nurse to understand the situation. It } \\
\text { involves the nurse asking for more } \\
\text { detail so that the situation can be } \\
\text { understood more fully. It shows the } \\
\text { older person that their thoughts and } \\
\text { feelings are important and the nurse } \\
\text { wants to gain thorough understanding }\end{array}$ \\
\hline
\end{tabular}

\section{Time Out 1}

Think about some recent conversations you have had with older people in our practice setting. How did you show that you were listening attentively to the other person? List three actions you could take to develop your active listening skills in practice. This might include discussing your practice with a colleague or using role play activities to practice your skills in a safe environment.

Central to effective communication is having the ability to know ourselves. Indeed, it is only when we know ourselves and our strengths and limitations that we can begin to know and help another. Making time through, for example, reflective activities to develop our self-awareness enables us to be more present in the therapeutic 
relationship and can enhance self-confidence and growth (Ellington et al 2017). Selfawareness is a central part of emotionally intelligent practice. Emotional intelligence is a concept, which became popular in the 1990's and is of great importance to interpersonal skills and the development of relationships with others (McQueen 2004). In their seminal work Mayer and Salovey (1995: 189) describe emotional intelligence as '...the ability to monitor one's own and other's feelings and emotions, to discriminate among them and to use this information to guide one's thinking and actions'. For example, working with older people often places us in emotionally difficult situations for example, caring for someone who is distressed, dealing with safeguarding issues or caring at the end of life. So it is important then, that we are able to recognize emotion in others and ourselves in order to guide our actions appropriately. For example, caring for an older person at end of life might bring back memories of loss of a member of our own family. Remembering the sadness we felt at our own loss might be used positively, for example, to support an empathic response to the current situation. However, there might be occasions when our grief influences us in a negative way to the extent that our emotions take over unhelpfully, making us incapable of caring for another. Having the ability to recognize our emotions and care for ourselves, is the first step to being able to manage them in a calm and professional manner and over time, reflective practice might support us in this developmental area. Thompson (2006) suggests some guidance for dealing with emotionally difficult situations as they are encountered and uses the acronym

SARAH as a guide (Table 2)

Table 2

'SARAH'

\begin{tabular}{|l|l|}
\hline S - Stop talking & $\begin{array}{l}\text { Attempt to listen carefully to what the } \\
\text { person is saying and resist the urge to } \\
\text { speak }\end{array}$ \\
\hline A - Actively listen & $\begin{array}{l}\text { Give the person an opportunity to speak } \\
\text { and encourage them using nonverbal } \\
\text { communication such as nodding and } \\
\text { small rewards such as 'Aha', 'I see' }\end{array}$ \\
\hline
\end{tabular}




\begin{tabular}{|l|l|}
\hline R - Reflect content & $\begin{array}{l}\text { Intermittently, reflect back what the } \\
\text { person is saying to show that you are } \\
\text { listening to what is being said }\end{array}$ \\
\hline A - Act with empathy & $\begin{array}{l}\text { Show the other person that you are with } \\
\text { them and that you recognize what they } \\
\text { are saying and how they are feeling }\end{array}$ \\
\hline $\mathrm{H}-$ Handle objections & $\begin{array}{l}\text { Listen to the other persons objections } \\
\text { and complaints and show willingness to } \\
\text { deal with them }\end{array}$ \\
\hline
\end{tabular}

\section{Time Out}

Identify three actions you intend to take to explore emotional intelligence further. These could include, for example, reading books on the topic or taking one of the freely available online assessments e.g. https://www.mindtools.com/pages/article/eiquiz.htm Write down these actions and put them somewhere you are likely to see them regularly until you have completed them.

\section{The effect of ageism}

It is important that practitioners communicate effectively with older people to ensure their needs are met. The 'communication predicament of ageing' described by Ryan et al (1986) exists when there is a discrepancy between an older person's actual communication competencies and those perceived by others. The World Health Organisation describe ageism as the 'stereotyping, prejudice and discrimination against people on the basis of their age' (www.who.int) and whilst most healthy older people do not lose the ability to communicate effectively, ageism remains a force to be reckoned with. Age Concern's (2004) report into ageism revealed how 1:3 people surveyed considered 'old' people to be 'incompetent' and 'incapable' and today ageism remains a problem with millennials in Britain holding the most negative attitudes towards ageing (RSPH \& The Calouste Gulbekian Foundation 2018). Ageism is harmful as it can lead older people to feel marginalised and excluded from society, which leads to detrimental effects on their health and wellbeing.

Practitioners might be at risk of stereotyping older people and making aged based assumptions about their ability to communicate and such attitudes can also result in 
older people applying negative stereotypes to themselves (Ryan et al 1986; RSPH \&The Calouste Gulbekian Foundation 2018) leading to lower expectations and perhaps a failure to maximise their potential. Described as 'elderspeak', using slower or louder speech, being patronising and simplifying sentences can have the effect of lowering the self-esteem of the older person and making them feel powerless (Ryan and Butler 1996). Ryan et al (1986) make reference to this style of communication as a process of 'overaccommodation' where practitioners, reliant on negative stereotypes of ageing, may use the kind of speech most usually associated with babies and children. The Communication Enhancement Model supports facilitating rather than directing interactions which match the level and needs of the older person rather than assuming that all older people will behave in a particular way (Ryan et al 1995). Central to this model is the nurse having the ability to, continually assess the older person; recognize cues on an individual basis; modify communication to accommodate individual needs. This approach is cyclical and has an empowering effect on the person involved in the conversation supporting positive changes in their well-being.

\section{Time Out 3}

Identify how your perceptions of ageing might have influenced the way in which you communicated with and older person. Did you make any assumptions about the person before you spoke with them? Review the ideas described above and consider how your practice might be developed in the future, based on these elements. How often do you continuously assess - recognize cues - modify your communication accordingly? List three improvements you could make to your practice after reviewing this model.

\section{Important Changes in the Older Person}

It is important to remember that older people are not a homogenous group; they have a wide range of life experiences that influence their perception of illness and their ability to communicate with healthcare professionals. Waterworth et al (2017) found that older people themselves sometimes attributed symptoms to ageing, deterring them from making contact with a health professional, and this was more likely when the older person was living with multiple health conditions. Nurses need to be mindful of personal and cultural differences and understand the older person's 
own preferences and wishes for care whilst considering any individual biological and social changes that can influence a consultation or relationship.

As people age there are changes in the appearance and functioning of individual cells and organs within the body and physiological changes occur in all body systems. Older people will experience changes in hearing and vision and whilst many healthy older people remain cognitively alert, those individuals who have had a stroke or live with a neuro-degenerative disorder such as Parkinson's or Alzheimer's disease will notice changes in the functioning of the brain with resulting difficulties in speech, language and cognition. Dysarthria, dysphonia, aphasia, difficulties with reading and writing, with regulating thinking and behaviour and with memory can all impair the older person's ability to communicate effectively with others. Dementia is predominantly a disease of older people with about $20 \%$ of those affected aged 85 or above (Alzheimer's Society 2014) and the degenerative nature of dementia means people can progress from forgetting for the names of people, places and objects to complete loss of language and decreased recognition of family and self. They may experience delusions and hallucinations and present as aggressive and agitated or withdrawn and overly compliant (Yorkston et al 2010).

Cognitive abilities are the mental skills people need to carry out any task and these skills include awareness, information handling, memory and reasoning. As people age, natural cognitive changes occur with older people experiencing more difficulties processing information (Williams 2013), forming or recalling new memories and coping well when divided attention is required such as talking on the phone whilst watching a television programme ( Alzheimer's Disease Research Center, 2018). Cognition can be influenced by other factors too; medication for conditions including diabetes, hypertension, anaemia and constipation have all been shown to affect cognitive performance and some types of prescription medicine can induce fatigue and confusion (Nevado-Holgado et al 2016). Cognitive impairment has also been associated with polypharmacy (Martin et al 2000; Jyrkka et al 2010). Defined as the administration of many drugs together, it is a growing concern for many older adults. Changes in vision in the older person include reduced visual acuity, presbyopia and disorders such as glaucoma, retinopathy, cataracts and macular degeneration. Age related hearing loss (presbycusis) is common in older people who can also 
experience tinnitus, conductive hearing loss and difficulty hearing high frequency sounds such as $\mathrm{f}, \mathrm{s}$, th, sh and ch. Many older people struggle to hear above loud background noise and mechanical issues such as impacted ear wax or hair growth in the ears can further impair hearing. The older someone is the more likely they are to have dual-sensory loss or multi-sensory impairment (Royal National Institute of Blind People 2018) adding to the difficulties they face when communicating with others.

Whilst depression is not an inevitable consequence of ageing, The Royal College of Psychiatrists (2018) report that depression can affect 1 in 5 older people living in the community and 2 in 5 living in care homes. This can result in problems with motivation, attention and memory all of which can negatively impact upon effective communication. Life changes such as bereavement, retirement and ill health can be associated with feelings of anxiety and distress and older people with depression may present as tired, irritable, withdrawn or confused. They may be reluctant to share concerns with nurses and struggle to verbalise their wishes and preferences for care and support. Medication side effects can further contribute to feelings of low mood. Depression can also be a contributor to or a maintaining factor for pain that is prevalent in many older people. Accurate assessment of pain is challenged in part by communication barriers including cognitive decline and socio-cultural factors (Schofield, 2018). Some older people may find difficult to express their pain in ways others can understand and can feel disempowered, afraid or hindered by organisational barriers such as time and place of care. Pain is driven by biological, bio-psychological and social forces (Hadjistavropoulos et al 2011) including chronic loneliness that also affects a large number of older people (Davidson and Rossall 2015) and social isolation has also been linked to cognitive decline and mental health conditions such as depression and dementia (Landeiro et al 2017).

\section{Time out 4}

\section{Reflection}

In order to support your revalidation requirements, download the reflective account template from the NMC website and reflect on an occasion from practice where communication with an older person was impaired by a problem such as sensory loss, dementia, pain or depression. 


\section{Enhancing communication in practice}

The ability to 'cure even with words' (Marconowitz et al 2014) highlights how improving communication with older people results in enhanced therapeutic relationships, better care and improved outcomes. It is important any barriers to meaningful communication are identified early and whilst it might not be feasible to remove all age related barriers, organisational and environmental factors might be modifiable and support a more successful interaction. The table below identifies some of the barriers that you might want to consider when communicating with an older person:

\begin{tabular}{|c|c|c|}
\hline Environmental barriers & Organisational barriers & Nurse related barriers \\
\hline $\begin{array}{l}\text { - } \text { Limited physical } \\
\text { - } \text { access } \\
\text { - } \quad \text { Interruptions } \\
\text { - } \quad \text { Noise } \\
\text { - Uncomfortable } \\
\text { - } \text { room temperature } \\
\text { - Untidy or } \\
\text { unhygienic } \\
\text { - environment } \\
\text { Unfamiliar } \\
\text { - } \quad \text { Menvironment } \\
\text { (Yorkston et al 2010; Park } \\
\text { and Song 2005; Daly } \\
\text { 2017) }\end{array}$ & $\begin{array}{l}\text { Short appointment times } \\
\text { Inflexible appointment } \\
\text { systems } \\
\text { Staff shortages } \\
\text { Lack of staff training } \\
\text { Mode of communication } \\
\text { e.g. telephone } \\
\text { consultation/face to face } \\
\\
\text { ( McGilton 2002; } \\
\text { Waterworth et al 2017) }\end{array}$ & $\begin{array}{l}\text { Ageist attitudes } \\
\text { Medical jargon } \\
\text { Interrupting the older } \\
\text { person as when are } \\
\text { talking } \\
\text { Poor eye contact } \\
\text { Poor listening skills } \\
\text { Unfriendly or } \\
\text { disrespectful attitudes } \\
\text { Lack of professional } \\
\text { knowledge } \\
\text { Giving too much } \\
\text { information at once } \\
\text { Speaking too quickly } \\
\text { Misuse of power }\end{array}$ \\
\hline
\end{tabular}




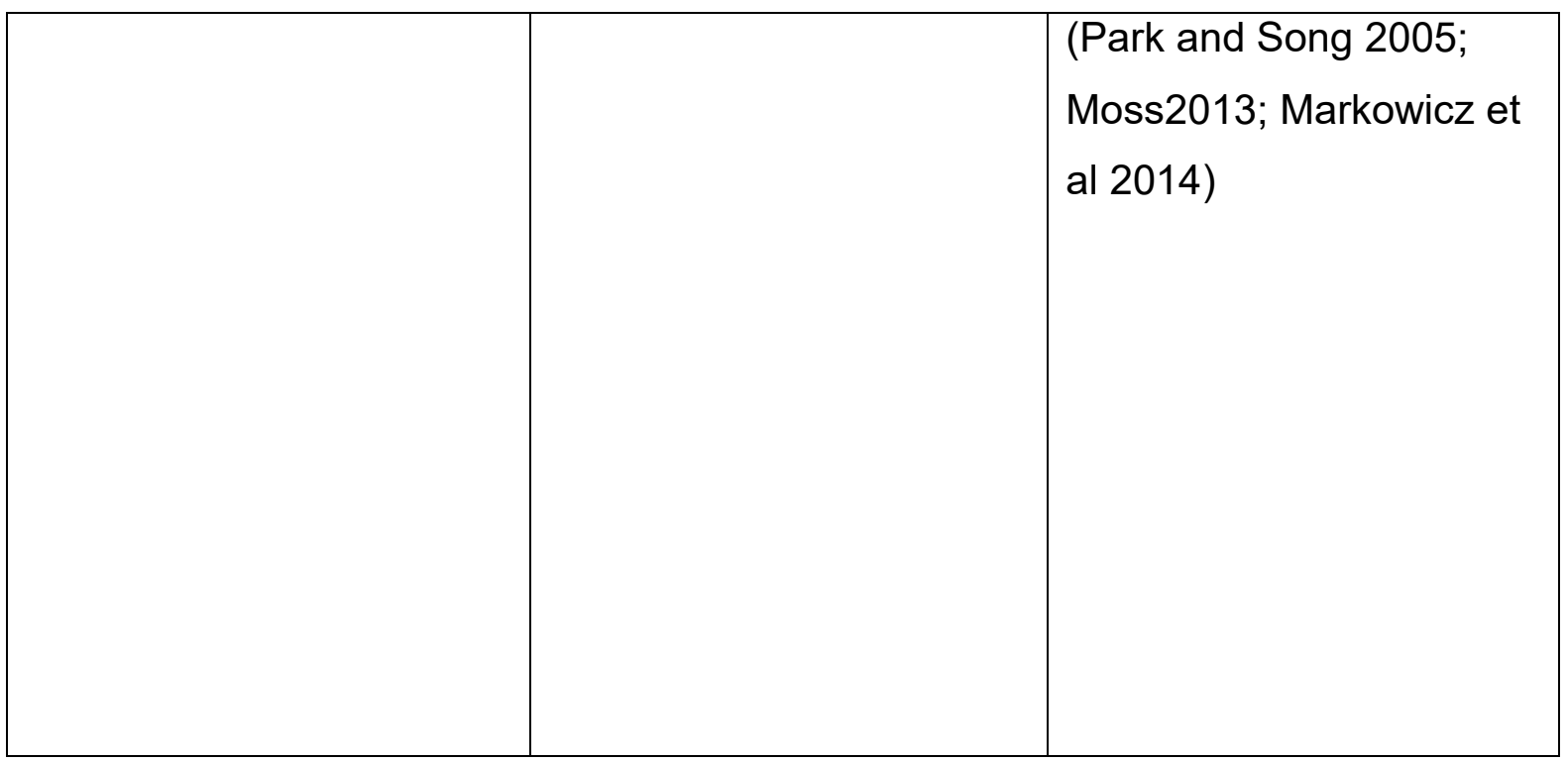

Once modifiable barriers have been considered and practitioners are 'plugged in' (Robinson et al 2006); in other words they are connected both emotionally and physically to the older person, then meaningful communication can begin. A person centred approach not only considers those barriers pertaining to the individual older person at the centre of care but considers their particular strengths, capabilities, cultural norms and values. Even older people who lack capacity under the terms of The Mental Capacity Act 2005 can, with respect and thoughtfulness benefit from personalised care. Person centred approaches to communication demand practitioners be mindful of their verbal and nonverbal skills and general strategies that support person centred communication can be found in Table 3 below.

Table 3

Strategies to support a person centred approach to communication

- Get to know the person; what are their wishes and preferences for care? What are their values beliefs and cultural norms?

- Focus on the older person's needs rather than the needs of the service

- Identify their perceived barriers to communication and reduce modifiable barriers as much as possible

- Be self-aware so that any personal barriers can be addressed. 
- Use appropriate communication methods to empower the older person to participate in their own care and be a partner in any decisions that are made.

- Be prepared to negotiate and compromise

- Avoid assumptions about older people's capacity to communicate effectively

- Make appropriate adjustments to accommodate physical or cognitive changes that might affect meaningful communication

- Prioritise the older person's safety, comfort and well-being uppermost in our mind. There is much

- For older people who lack capacity, engage with trusted family and friends and consider any communication with advanced directives

\section{Technology and enhanced communication}

Digital health technology encompasses a wide range of applications and interventions with the potential to improve the health needs of older people. The NHS's Five Year Forward View that commits to harnessing innovation (DH 2014) means technology is now fast becoming an integral part of the future for communication in health and social care with perceived benefits for both older people's physical and mental wellbeing (The Kings Fund, 2016). Whilst not every older person will want to engage with technology as a form of communication and others will need support in order to cope with technological advances, it is important not to make assumptions, as some older people will want to be involved and have sophisticated skills and a good level of capability. Data from Age UK (2018) reveals a significant rise in the proportion of older people using the internet, with most activity in the 65-74 year age group related to communication.

Innovative technologies such as pulse oximeters, blood pressure monitors and blood glucose meters are helping older people manage their conditions more effectively. Health and fitness application systems on smartphones and tablets have the potential to improve health and wellbeing. Access to personal health records support older people's independence, empower them to take control of their health 
(Ham 2018) and can even reduce isolation. Improved contact and communication with older people through initiatives like Patient Online enable older people to have more control over when they see their GP or practice nurse. It can support them to access clinical correspondence such as hospital discharge summaries, outpatient appointment letters and referral letters (NHS 2018). Medication reminders and safety alerts via text, email or smartphone application systems can reduce hospitalisation and other general benefits of ICT include better communication and co-ordination between older people and their care providers, reduced caregiver burden and increased overall patient satisfaction (Center for Technology and Aging 2011).

\section{Time Out 5}

In your own place of work how might you use ICT to enhance communication with older people? What training or support might older people need to engage fully with any systems in place to ensure they are accessible and beneficial?

\section{Conclusion}

As the number of older people continues to grow, effective communication has become an increasingly important aspect of nursing practice. Older people are not only living longer but often with multiple co-morbidities and will need to access health care more frequently than ever before. Communication with the older person can sometimes be difficult due to the effects of ageing such as loss of hearing and sight. However there are orgnisational, cultural and nurse related barriers that can often be mitigated with some changes to practice. Such changes can have an empowering effect on the older person as when communication is effective, they feel cared for, respected and more able to describe their concerns. Ongoing personal reflection is important if nurses are going to remain self-aware and resistant to older stereotypes, which can be damaging and detrimental to care of the older person. Monitoring our own communication style so that it is therapeutic in nature rather than transactional, can make a huge difference to older person's care in terms of its effectiveness and can also support the nurses own well-being and health.

\section{References}


Age UK (2018) Later Life in the United Kingdom Online

https://www.ageuk.org.uk/globalassets/age-uk/documents/reports-and-

publications/later life uk factsheet.pdf Accessed 09-09-2018

Alzheimer's Disease Research Center (2018) Cognitive Skills and Normal Aging http://alzheimers.emory.edu/healthy aging/cognitive-skills-normal-aging.html

Alzheimer's Society (2014) Dementia UK Report

https://www.alzheimers.org.uk/about-us/policy-and-influencing/dementia-uk-report (last accessed 26/08/2018)

Bochner S (2013) Cultures in Contact: Studies in Cross Cultural-Interaction Oxford: Pergamon Press

Center for Technology and Aging (2011) mHealth Technologies: Applications to Benefit Older Adults Online

http://www.phi.org/uploads/application/files/ghcah59qtuhe4ighf3h7kp12v7q8xv15quh 6u99569k1zuzce7.pdf Accessed 09-09-2018

Croston, M. (2018) 'Communication' In Tetley, J., Cox, N., Jack, K. and Witham, G. (eds.) Nursing Older People at a Glance. Wiley-Blackwell: Oxford. pp. 6-7.

Davidson, S and Rossall P (2015) Evidence Review: Loneliness in Later Life https://www.ageuk.org.uk/globalassets/age-uk/documents/reports-andpublications/reports-and-briefings/health-wellbeing/rb june15 lonelines in later life evidence review.pdf (last accessed 26/08/2018)

Daly, L (2017), Effective communication with older adults Nursing Standard. 31, $41,55-62$

DH (2014) Five year Forward View Online https://www.england.nhs.uk/wpcontent/uploads/2014/10/5yfv-web.pdf (Accessed 09-09-2018)

Department for Work and Pensions (2011) Number of Future Centurions by Age Group. London: DWP

Dickson M, Riddell H, Gilmore F \& McCormack B (2017) Delivering dignified care: A realist synthesis of evidence that promotes effective listening to and learning from 
older people's feedback in acute care settings Journal of Clinical Nursing 26, 4028 4038

Ellington L, Billitteri J, Reblin M \& Clayton MF (2017) Spiritual Care Communication In Cancer Patients Seminars in Oncology Nursing. 33, 5, 517 - 525

Hadjistavropoulos T, Craig DK, Duck S et al (2011) A biopsychosocial formulation of pain communication. Psychology Bulletin. 13, 910-39.

Hafskjold L, Eide T, Holmstrom IK, Sundling V, van Dulmen S \& Eide H (2016) Older persons' worries expressed during home care visits: Exploring the content of cues and concerns identified by the Verona coding definitions of emotional sequences Patient Education and Counselling 12, 1955 - 1963

Ham C (2018) Using technology to build a partnership of trust with patients Online https://www.kingsfund.org.uk/blog/2018/09/using-technology-build-partnership-trustpatients

(Accessed 08-09-2018)

Hammar, LM.,Holström, IK., Skoglund, K., Meranius, MS. \& Sundler AJ. (2017) The care and communication with older people from the perspective of student nurses. $A$ mixed method study. Nurse Education Today, 52 pp. 1-6.

Hanson RM (2014) 'Is elderly care affected by nurse attitudes?' A systematic review. British Journal of Nursing 23, 4 225-229

Harrison R, Walton M, Healy J, Smith-Merry J, \& Hobbs C (2016) Patient complaints about hospital services: Applying a complaint taxonomy to analyse and respond to complaints. International Journal for Quality in Health Care 28, 2, 240-245

Jyrkka J, Enlund H, Lavikainen P, et al.( 2010) Association of polypharmacy with nutritional status, functional ability and cognitive capacity over a three-year period in an elderly population. Pharmacoepidemiology and Drug Safety. 2, 514-522.

Landeiro F, Barrows P, Nuttall Musson E, et al (2017) Reducing social isolation and loneliness in older people: a systematic review protocol. https://bmjopen.bmj.com/content/7/5/e013778 (last accessed 26/08/2018) 
Markinowicz L, Pawlikowska T and Oleszczyk M (2014) What do older people value when they visit their general practitioner: A qualitative study European Journal of Ageing. 11, 4, 361-367

Martin NJ, Stones MJ, Young JE, et al (2000) Development of delirium: a prospective cohort study in a community hospital. International Psychogeriatrics.12, 117-27.

Mayer JD and Salovey P (1995) Emotional intelligence and the construction and regulation of feelings Applied and Preventive Psychology 4, 197 - 208

McGilton KS (2002) Enhancing relationships between care providers and residents of long term care. Designing a model of care Journal of Gerontological Nursing 28, $13-21$

McQueen ACH (2004) Emotional intelligence in nursing work Journal of Advanced Nursing 47, 1, $101-108$

Moss B (2012) Communication Skills in Health and Social Care London Sage NHS (2018) Start using GP online services Online https://www.nhs.uk/using-thenhs/nhs-services/gps/gp-online-services/\# Accessed 09-09-2018

Nursing \& Midwifery Council (2015) The Code: Professional Standards of Practice and Behaviour for Nurses and Midwives. London: NMC

Nevado-Holgado AJ, Kim, CH, Winchester L, Gallacher J and Lovestone S (2016) Commonly prescribed drugs associate with cognitive function: a cross sectional study in UK Biobank. BMJ Open

Office for National Statistics Population Estimates for the UK, England and Wales, Scotland and Northern Ireland: mid 2017 (2018)

https://www.ons.gov.uk/peoplepopulationandcommunity/populationandmigration/pop ulationestimates/bulletins/annualmidyearpopulationestimates/mid2017 (last accessed 26/08/2018) 
Park EK \& Song M (2005) Communication barriers perceived by older patients and nurses International Journal of Nursing Studies. 42, 159-166

Public Health England (2018) Health Profile for England: 2018

https://www.gov.uk/government/publications/health-profile-for-england-2018 (last accessed 15/9/18)

Robinson, TE, White, GL and Houchins JC (2006) Improving communication with older patients: tips from the literature Family Practice Management; September 7378

Royal College of Psychiatrists (2018) Depression in Older Adults. https://www.rcpsych.ac.uk/healthadvice/problemsanddisorders/depressioninolderadu Its.aspx (last accessed 26/08/2018)

Royal National Institute of Blind People (2018) Dual Sensory Loss

https://www.rnib.org.uk/eye-health/sight-loss-and-other-conditions/dual-sensory-loss (Last accessed 26/08/2018)

Royal Society Public health/ The Calouste Gulbekian Foundation (2018) That Age Old Question: How attitudes to ageing affect our health and wellbeing Online:

https://www.rsph.org.uk/uploads/assets/uploaded/010d3159-0d36-4707aee54e29047c8e3a.pdf

$(31 / 08 / 2018)$

Ryan EB, Giles H, Bartolucci G \& Henwood K (1986) Psycholinguistic and psychological components of communication by and with the elderly. Language and Communication $6,1 / 2,1-24$

Ryan EB, Meredith SD, MacLean MJ \& Orange JB (1995) Changing the way we talk with elders: Promoting health using the communication enhancement model The International Journal of Ageing and Human Development 41, 2, 89 - 107

Ryan EB \& Butler RN (1996) Communication, ageing and health: Towards understanding health providers relationships with older clients. Health Communication 8, 191 - 197 
Schofield, P (2018) The Assessment of Pain in Older People: UK National Guidelines https://www.ncbi.nlm.nih.gov/pmc/articles/PMC5888957/ (last accessed 26/08/2018)

Schroyen S, Adam S, Marquet M, Jerusalem G, Thiel S, Giraudet AL \& Missotten P (2017) Communication of Healthcare Professionals: Is there ageism? European Journal of Cancer Care 27: e12780

Stockmann C, Gabor O, DiVito-Thomas P, \& Ehlers C (2016) The Use and Intended Outcomes of Presence: A Focus Group Study International Journal of Nursing Knowledge 29, 1, 59-65

The King's Fund (2016) The digital revolution: eight technologies that will change health and care Online https://www.kingsfund.org.uk/publications/eight-technologieswill-change-health-and-care

(Accessed 08-09-2018)

The World Health Organisation (2018) Ageing and Life Course http://www.who.int/ageing/ageism/en/ (last accessed 16 ${ }^{\text {th }}$ June 2018) Thompson N (2006) People Problems. Basingstoke Palgrave Macmillan Tolson D and Brown Wilson C (2012) Communication. In Reed J, Clarke C, Macfarlane A (Eds) Nursing Older Adults. Open University Press, Maidenhead, 159175.

Trevithick P (2010) Social work skills: A Practice Handbook Maidenhead OU Press Waterworth S, Raphael D, Parsons J and Arroll B (2017) Older people's experiences of nurse-patient telephone communication in the primary healthcare setting Journal of Advanced Nursing 74, 373-382

Williams, K (2013) Evidence based strategies for communicating with older adults in long term care. Journal of Clinical Outcomes Management 20, 11, 507-512

Yorkston K, Bourgeios M and Baylor C (2010) Communicating and aging https://www.ncbi.nlm.nih.gov/pmc/articles/PMC3074568/ (Last accessed 26/08/2018) 